\title{
SEROPREVALENCE OF IgM ANTIBODIES IN CYTOMEGALOVIRUS INFECTIONS IN PREGNANT WOMEN WITH BAD OBSTETRIC HISTORY ATTENDING GOVERNMENT MATERNITY HOSPITAL, TIRUPATI.
} \author{
N. Rama Krishna ${ }^{7}$ \\ ${ }^{1}$ Assistant Professor, Department of Microbiology, SVMC, Tirupati, Andhra Pradesh, India. \\ 2Senior Resident, Department of Microbiology, SVIMS, Tirupati, Andhra Pradesh, India. \\ ${ }^{3}$ Associate Professor, Department of Microbiology, ACSRGMC, Nellore, Andhra Pradesh, India. \\ ${ }^{4}$ Professor, Department of Microbiology, Apollo Medical College, Chittoor, Andhra Pradesh, India. \\ ${ }^{5}$ Assistant Professor, Department of Microbiology, SVMC, Tirupati, Andhra Pradesh, India. \\ ${ }^{6}$ Medical Officer, Air Force Hospital, Bangalore, Karnataka, India. \\ ${ }^{7}$ Assistant Professor, Department of Microbiology, SVIMS, Tirupati, Andhra Pradesh, India.
}

Boddu Mahalakshmi ${ }^{1}$, Sharabu Yamini², Gandikota Rajaram³ 3 , B. Kailasanatha Reddy4, Jakka Naga Sudha Rani ${ }^{5}$, Ediga Veera Lavanya ${ }^{6}$,

ABSTRACT

\section{BACKGROUND}

Maternal infections play a crucial role in pregnancy wastage, which are transmitted in utero during pregnancy. The TORCH infections are the most significant of all infections causing morbidity and mortality. Primary infection with Cytomegalovirus (CMV) is one of the most common congenital viral infections. Although, $90 \%$ of congenital infections are asymptomatic, 5 to $17 \%$ of infants born to mothers with primary CMV infection will be overtly symptomatic and have a mortality rate of $30 \%$ and severe neurological morbidity occurs in $90 \%$ of survivors. Acute CMV infection can be diagnosed by detection of antibodies by serology and by detection of CMV genomic sequences by RT-PCR. Seroconversion or significant rise in the titre of CMV IgM indicates recent CMV infection and may still be detected upto one year even if the individual presents after the symptoms have subsided. Hence, the present study was carried out.

This study aims to screen antenatal women for IgM antibodies to CMV by ELISA and to study the seroprevalence of CMV in antenatal women. Further, the seropositivity was correlated with bad obstetric history cases in antenatal women.

\section{MATERIALS AND METHODS}

An observational cross-sectional study was conducted in a Government Maternity Hospital, Tirupathi, for a period of one year. By using a convenient sampling method, a total of 186 blood samples were collected from antenatal women with bad obstetrics history who attended during the period of July 2011 to Jan 2012. All samples collected were processed and screened for CMV specific IgM antibodies by Enzyme-Linked Immunosorbent Assay (ELISA) using "Anti-CMV IgM ELISA" kit of Euroimmune following the manufacturer's instructions. Chi-square test was applied to check the significance level. Finally, results were displayed in terms of percentages, bar diagrams, pie diagrams and tables.

\section{RESULTS}

A total number of 186 blood samples were collected and processed. Samples were screened for IgM antibodies against CMV using Anti-CMV IgM kit by ELISA as per the manufacturer's instructions. Of the 186 samples tested, 156 were from antenatal women with BOH (test group) and the remaining 30 were from the women with previous normal deliveries (control group). Of the test group, $12(7.69 \%)$ serum samples were found to be positive for IgM antibodies to CMV. Among the control group, no sample was found to be positive for IgM antibodies to CMV.

\section{CONCLUSION}

It is concluded that CMV infections are responsible for some obstetrical losses. There is no vaccine for prevention and there is no way to prevent foetuses from being infected once the mother acquires the infection. It is suggested that women in the reproductive age group should be screened for CMV infections. It is observed that universal screening of pregnant women for CMV infection during an early prenatal visit is not yet recommended worldwide.

\section{KEY WORDS}

Antenatal Women with BOH, Cytomegalovirus (CMV), Enzyme-Linked Immunosorbent Assay (ELISA), IgM Antibodies to CMV. HOW TO CITE THIS ARTICLE: Mahalakshmi B, Yamini S, Rajaram G, et al. Seroprevalence of IgM antibodies in cytomegalovirus infections in pregnant women with bad obstetric history attending Government Maternity Hospital, Tirupati. J. Evolution Med. Dent. Sci. 2018;7(47):5094-5097, DOI: 10.14260/jemds/2018/1132

'Financial or Other Competing Interest': None.

Submission 09-10-2018, Peer Review 02-11-2018,

Acceptance 09-11-2018, Published 19-11-2018.

Corresponding Author:

Sharabu Yamini,

Senior Resident, Department of Microbiology,

SVIMS, Tirupati, Andhra Pradesh, India.

E-mail: sharabuyamini@gmail.com

DOI: $10.14260 /$ jemds $/ 2018 / 1132$

(c) (i) $\odot$

\section{BACKGROUND}

Cytomegalovirus (CMV) is the most common congenital viral infections with birth prevalence range of $0.2-2.5 \%$.(1) The seroprevalence is heavily dependent on geographical location, social status and age.(2) Universal screening of pregnant women for CMV infection during an early prenatal visit is not yet recommended worldwide. Studies found that the rate of CMV transmission increased throughout pregnancy and it was approximately 36,44 and $77 \%$ for the first, second and third trimesters respectively.(3) It is also 
observed that severe sequelae are most common with primary infection acquired in the first half of pregnancy.(4) Preventing CMV infection is difficult, because the virus is so ubiquitous and infection occurs so commonly. However, personal hygienic precautions will reduce the risk of transmission of the virus in pregnant women or in those who are trying to become pregnant. These precautions include(5)avoid mouth kissing of children, not to share eating or drinking utensils, drinks with other children, intimate contact with the sexual partner who is a known CMV seropositive and to practice careful hand washing or using gloves after wiping noses and other discharges.

The usual manifestations of overt CMV infection at birth are hepatosplenomegaly, jaundice, thrombocytopenia and various congenital malformations, especially those involving the central nervous system. Acute CMV infection can be diagnosed by detection of antibodies by serology and by detection of CMV genomic sequences by RT-PCR.(6) Seroconversion or significant rise in the titre of CMV IgM indicates recent CMV infection and may still be detected upto one year even if the individual present after the symptoms have subsided. If the CMV IgM level is high at presentation and a rise in titre cannot be demonstrated, the presence of CMV IgM is used to determine acute CMV infection.

With the above-mentioned ideas, a study was carried out in the Department of Microbiology, S. V. Medical College, Tirupati, to explore the seroprevalence of CMV IgM antibodies among antenatal women with bad obstetric history attending the antenatal clinic at Government Maternity Hospital, Tirupathi during the period from July 2011 to December 2011.

\section{MATERIALS AND METHODS}

An observational cross-sectional study was conducted in a Government Maternity Hospital, Tirupathi, for a period of one year. By using a convenient sampling method, a total of 186 blood samples were collected from antenatal women with bad obstetrics history who attended during the period of July 2011 to Jan 2012. The blood samples were processed in the Department of Microbiology, Sri Venkateswara Medical College, Tirupati. A total of 156 blood samples were collected from the antenatal women with previous bad obstetric history as test group and 30 blood samples were collected from the antenatal woman with normal pregnancy outcome in previous pregnancies as the control group. Five millilitres of venous blood was drawn from each woman. The blood was drawn from antecubital vein by using a sterile disposable syringe and needle by observing aseptic precautions. The blood was allowed to clot. The serum was separated and stored at $-20^{\circ} \mathrm{C}$ until tested. All the samples were screened for CMV specific IgM antibodies by Enzyme Linked Immunosorbent Assay (ELISA) using "Anti-CMV IgM ELISA" kit of Euroimmune following the manufacturer's instructions. Results evaluated by calculating a ratio of extinction value of the control or patient sample $\div$ extinction value of calibrator following guidelines.

\section{Data Analysis}

Data was entered into Excel sheets and analysed using SPSS Software version 18. Chi-square test was applied to check the significance level. Finally, results were displayed in terms of percentages, bar diagrams, pie diagrams and tables.

\section{Ethical Considerations}

Institutional Ethics Committee approval and informed consent from study participants was obtained before conduct of the study. Data was collected with the help of pre-designed, semi-structured, closed ended questionnaire by a face-face interview. Study participants were explained regarding the study and purpose of conduct of study and their queries were answered satisfactorily.

\section{RESULTS}

Samples were screened for IgM antibodies against CMV using Anti-CMV IgM kit by ELISA, as per the manufacturer's instructions. Of the 186 samples tested, 156 were from antenatal women with $\mathrm{BOH}$ (test group) and the remaining 30 were from the women with previous normal deliveries (control group). Of the test group, 12 (7.69\%) serum samples were found to be positive for IgM antibodies to CMV. Among the control group, no sample was found to be positive for IgM antibodies to CMV ( $p>0.5$ ).

Twelve antenatal women with previous bad obstetric history were found to be positive for IgM antibodies to CMV. Thus, the seroprevalence for CMV was $7.69 \%$. All serum samples collected from antenatal women without bad obstetric history were found to be negative for $\operatorname{IgM}$ antibodies to CMV as shown in Table I.

\begin{tabular}{|c|c|c|c|}
\hline Group & $\begin{array}{c}\text { Number of } \\
\text { Samples } \\
\text { Tested }\end{array}$ & $\begin{array}{c}\text { Number } \\
\text { of } \\
\text { Positives }\end{array}$ & $\%$ \\
\hline $\begin{array}{c}\text { Test group: Antenatal } \\
\text { women with previous bad } \\
\text { obstetric history }\end{array}$ & 156 & 12 & $7.69 \%$ \\
\hline $\begin{array}{c}\text { Control: Antenatal women } \\
\text { without bad obstetric } \\
\text { history in the previous } \\
\text { pregnancy }\end{array}$ & 30 & NIL & NIL \\
\hline \multicolumn{2}{|c|}{ Table I. Seroprevalence of IgM Antibodies to CMV } \\
\hline
\end{tabular}

Figure 1 depicts that the seropositivity was highest in women of 31 years and above (17\%) and least $(2.7 \%)$ between 18-25 years, $(\mathrm{p}<0.03)$.

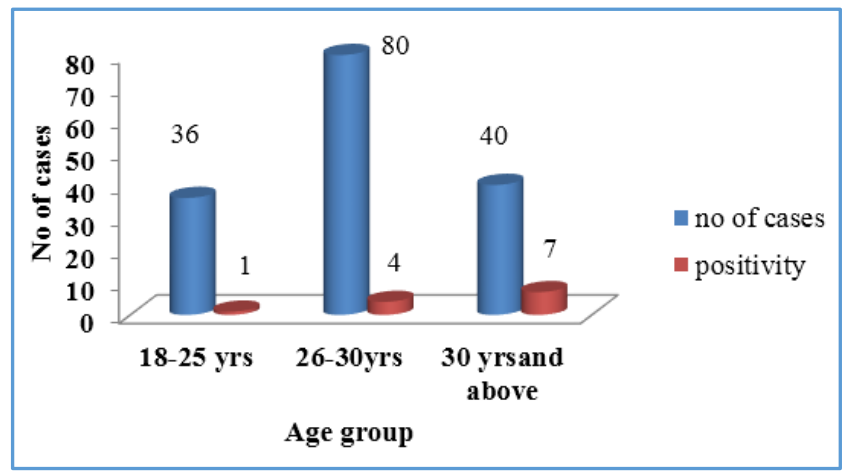

Figure 1. Seroprevalence as per Age

Figure 2 depicts that $\mathrm{CMV}$ is more prevalent in rural population $(8.47 \%)$ than in urban population $(7.21 \%)$, $(\mathrm{p}<0.05)$. From Figure 3, it was observed that the incidence of CMV seropositivity was highest in multiparous women $(66.6 \%)$ followed by women with $2-3$ pregnancies $(25 \%)$, $(\mathrm{p}<$ $0.02)$. 


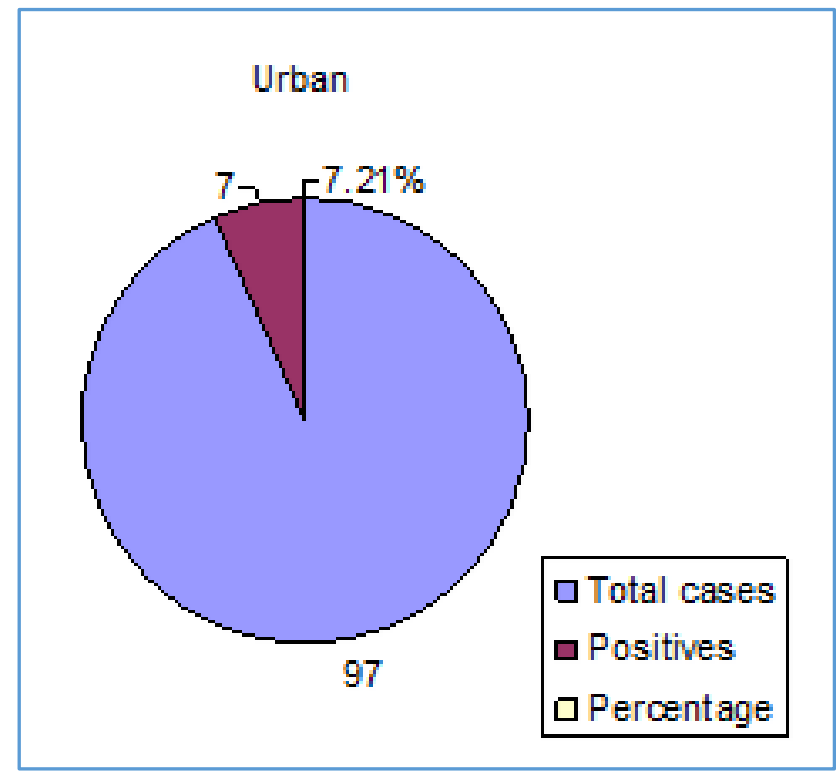

Figure 2. Seroprevalence of CMV Seropositivity in Urban and Rural Population

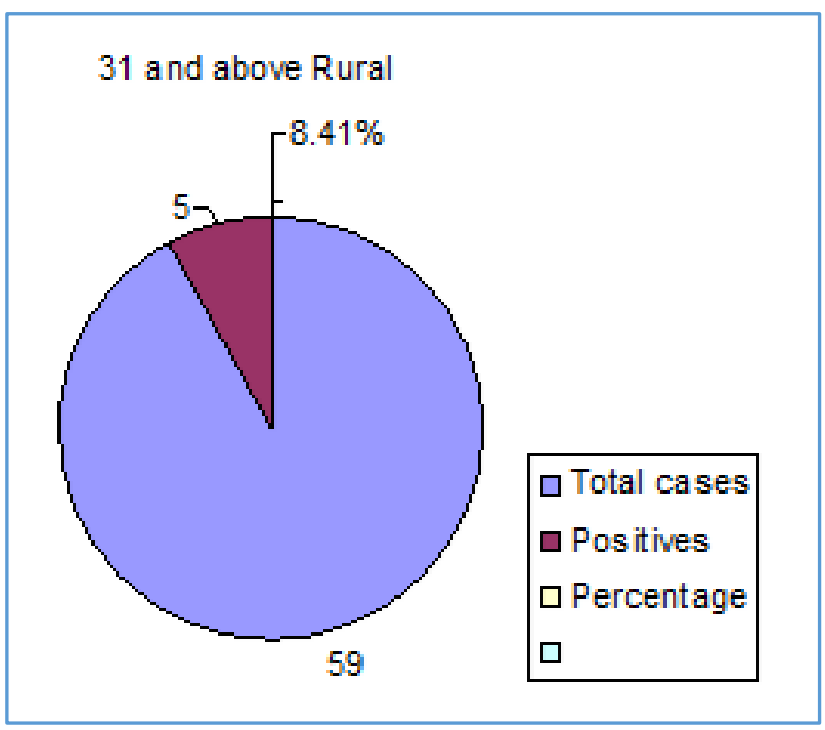

Figure 3. Seroprevalence of CMV Seropositivity as per Gravida

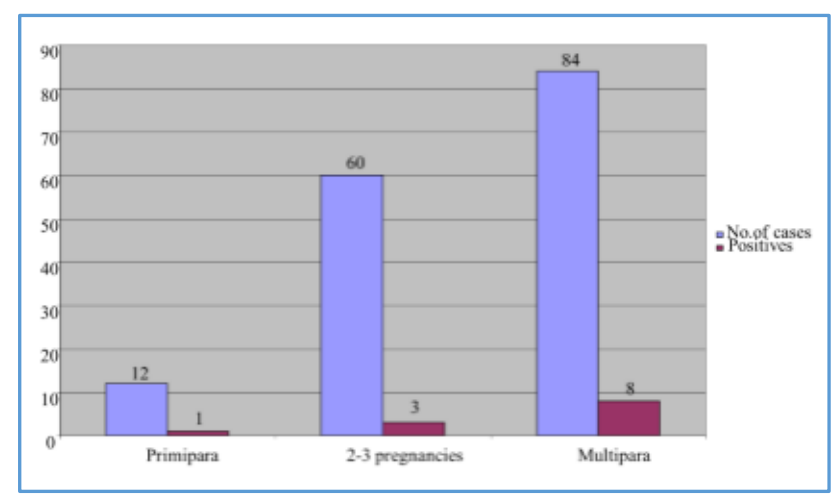

It was observed that seropositivity was highest in third trimester $(11.11 \%)$ followed by second trimester (5.5\%) (Fig. 4). It was also observed that the highest percentage of seropositivity is observed in case of repeated abortions $(9.75 \%)$ followed by still births $(7.14 \%)$ and abortion with IUD $(7.69 \%)(\mathrm{p}<0.01)$ (Table II).

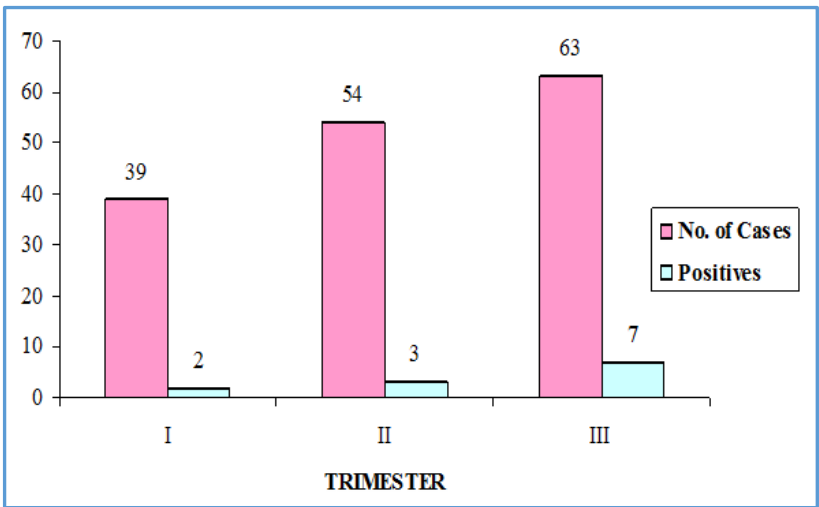

Figure 4. Seroprevalence as per Trimester

\begin{tabular}{|c|c|c|c|}
\hline $\begin{array}{c}\text { Bad Obstetric } \\
\text { History }\end{array}$ & $\begin{array}{c}\text { No. of Samples } \\
\text { Tested }\end{array}$ & \begin{tabular}{|c|} 
No. of \\
Positives \\
\end{tabular} & $\%$ \\
\hline Repeated abortions & 82 & 8 & $9.75 \%$ \\
\hline Intrauterine deaths & 26 & 1 & $3.85 \%$ \\
\hline $\begin{array}{l}\text { Preterm delivery with } \\
\text { IUD }\end{array}$ & 8 & NIL & NIL \\
\hline $\begin{array}{c}\text { Preterm delivery } \\
\text { with repeated abortions }\end{array}$ & 5 & NIL & NIL \\
\hline PROM & 1 & NIL & NIL \\
\hline $\begin{array}{c}\text { Congenital } \\
\text { malformations }\end{array}$ & 1 & NIL & NIL \\
\hline Stillbirths & 14 & 1 & $7.14 \%$ \\
\hline Abortion with IUD & 19 & 2 & $5.26 \%$ \\
\hline Total & 156 & 12 & $7.69 \%$ \\
\hline \multicolumn{4}{|c|}{$\begin{array}{c}\text { Table 2. The Results among various Subgroups of Bad } \\
\text { Obstetric History }\end{array}$} \\
\hline
\end{tabular}

\section{DISCUSSION}

Studies of Turbadkar et al(7) on the seroprevalence of TORCH infections in 308 women with $\mathrm{BOH}$ in a general public hospital, Mumbai, over one-year period for IgM seropositivity to CMV by ELISA method observed the presence of IgM antibodies in 32 cases $(8.42 \%)$ for CMV, which correlates with my study. Surpam et al(8) did a serological study for TORCH infections in 150 pregnant women with bad obstetric history, wherein the seroprevalence for CMV was 5.33\% and maximum number of cases were between 26 and 30 years. Results of the present study are nearly in concurrence with the above studies regarding age group. In the present study, the seropositivity observed was highest in women of 31 years and above $(17 \%)$ and maximum no. of cases were in the age group of 26-35 years. In the present study, it is noted that CMV is more prevalent in rural population $(8.47 \%)$ than in urban population $(7.21 \%)$.

Studies by Yasodhara et al,(9) on prevalence of specific IgM due to Toxoplasma, Rubella, CMV and C. trachomatis showed seropositivity for CMV to be $5.8 \%$ and majority of cases were multiparous women. It is noted that the prevalence for CMV seropositivity is highest $(66.6 \%)$ in multiparous women followed by $(25 \%)$ in women with $2-3$ pregnancies in the present study.

In the present study seropositivity in case of stillbirths is $7.14 \%$, which is in concurrence with studies by Kumari et $a l,(10)$ which showed $8.3 \%$ in case of $\mathrm{BOH}$ due to stillbirths. It is also observed that the seroprevalence of IgM for CMV has been increased with increase in gestational age. In the present study, seropositivity is highest in third trimester (11.11\%) followed by second trimester (5.5\%). Bodeus et al 
from Belgium did a study to determine whether the rate of human CMV transmission in utero is related to the gestational age at the time of maternal infection. Seroconversion during the first trimester and during the third trimester were $36.0 \%$ and $77.6 \%$ respectively. The risk of transmission calculated for seroconversion during the second trimester was intermediate (44.9\%), which correlates with my study.

In the present study seropositivity in case of stillbirths is $7.14 \%$, which is in concurrence with studies by Kumari et al, which showed $8.3 \%$ in case of BOH due to still births. Hence, it is recommended that in order to prevent congenital CMV infection, pregnant women should be educated about preventive measures, strict hygiene practices such as hand washing and careful cleansing of environmental surfaces. Since primary infections are more likely than non-primary infections to cause symptoms at birth and long-term disability, especially severe disability, there remains an urgent need for interventions that can prevent primary CMV infections among pregnant women. The results of the present study indicate that all antenatal cases with bad obstetric history should be routinely screened for CMV infection as early diagnosis, appropriate intervention and regular followup will help in proper management and good foetal outcome.

\section{CONCLUSION}

CMV infections are responsible for some obstetrical losses. There is no vaccine for prevention and there is no way to prevent foetuses from being infected once the mother acquires the infection. It is suggested that women in the reproductive age group should be screened for CMV infections. It is observed that universal screening of pregnant women for CMV infection during an early prenatal visit is not yet recommended worldwide. It is recommended to focus more on this to improve the foetal outcome. As seroprevalence for CMV is observed to be more in rural people and among elderly pregnant women, it is to be emphasised to them about the hygienic practices and see that regular health advice reaches these people. It is highly recommended to adopt more appropriate and more accurate diagnostic methods to detect primary CMV infections in pregnancy. This in turn improves early diagnosis and better foetal outcome. More research is recommended on CMV with an aim to develop a vaccine against CMV to immunise all adolescent girls and/or women of child bearing age before conception to reduce the incidence of CMV infections.

\section{REFERENCES}

[1] Kenneson A, Cannon MJ. Review and meta-analysis of the epidemiology of congenital cytomegalovirus (CMV) infection. Rev Med Virol 2007;17(4):253-76.

[2] Staras SA, Dollard SC, Radford KW. Seroprevalence of cytomegalovirus infection in the United States, 19881994. Clin Infect Dis 2006;43(9):1143-51.

[3] Bodeus M, Hubinont C, Goubau P. Increased risk of cytomegalovirus transmission in utero during late gestation. Obstet Gynecol 1999;93(5 Pt 1):658-60.

[4] Hagay ZJ, Biran G, Ornoy A, et al. Congenital cytomegalovirus infection: a long-standing problem still seeking a solution. Am J Obstet Gynecol 1996;174(1 Pt 1):241-5.

[5] Nigro G, Anceschi MM, Cosmi EV, et al. Clinical manifestations and abnormal laboratory findings in pregnant women with primary cytomegalovirus infection. BJOG 2003;110(6):572-7.

[6] Demmler GJ, Buffone GJ, Schimbor CM, et al. Detection of cytomegalovirus in urine from newborns by using polymerase chain reaction DNA amplification. J Infect Dis 1988;158(6):1177-84.

[7] Turbadkar D, Mathur M, Rele M. Seroprevalence of torch infection in bad obstetric history. Ind J Med Microbiol 2003;21(2):108-10.

[8] Surpam RB, Kamalakar UP, Khadse RK, et al. Serological study for TORCH infections in women with bad obstetric history. Journal of Obstetrics and Gynecology of India 2006;56(1):41-3.

[9] Yasodhara P, Ramalakshmi BA, Naidu AN, et al. Prevalence of specific IGM due to Toxoplasma, Rubella, CMV and C. trachomatis infections during pregnancy. Indian Journal of Medical Microbiology 2001;19(2):52-6.

[10] Kumari N, Morris N, Dutta R. Is screening of TORCH worthwhile in women with bad obstetric history? An observation from eastern Nepal. J Health Popul Nutr 2011;29(1):77-80. 